\title{
Advance Care Planning: Putting an End to the Agonizing Perpetuation of a Pointless Debate
}

\author{
Jürgen in der Schmitten \\ Institute of General Practice, Medical Faculty, Heinrich Heine University of Düsseldorf, Germany
}

Advance Directives (ADs) or living wills were first proposed in 1969 by a lawyer [1], appreciating the uncertain outcome and possible devastating burden and sequelae of potentially life-prolonging treatments initiated in patients incapable of consenting at that moment, and the necessity to offer individuals advance involvement in the hypothetical decision whether and under which circumstances to initiate, withhold, or withdraw such treatments.

Since then, ADs have been subject of constant debate. Countless papers have pointed out that ADs (the way they are traditionally conceived) have numerous theoretical flaws, and constitute an empirical failure. In the US, legislation of 1991 strengthened the role of ADs and directed public resources to advance their distribution, but the results were disappointing. Summing up the overwhelming evidence failing to support traditional ADs, ethicists have declared 'the failure of the living will' and consequently suggested to abandon the concept of ADs altogether [2].

The debate, however, runs in a circle. Our perplexity facing decisions to withhold or withdraw life-sustaining treatments in incompetent patients has grown, not diminished since 1969. As a secular, pluralistic society we seem to be committed to an 'imperative of the feasible', principally prepared to provide every treatment not literally futile to every incapable patient, almost regardless of age, state, and prognosis - despite the empirical fact that many patients would have opted otherwise had we given them the choice [3]. As flawed as ADs may be, no better means of allowing patients to opt out of the maximal treatment default have been suggested, therefore they remain in the debate.

This has to be borne in mind when appreciating the study by Hubert and colleagues presented in this issue [4]. In a selfdesigned questionnaire survey, a remarkable $81.5 \%$ of the invited 617 patients of a German university hospital's oncologic outpatient department answered questions relating to ADs. $31 \%$ stated to have a written $\mathrm{AD}$, an increase compared with earlier surveys among comparable populations which the authors attribute to the German legislation on ADs of 2009 and/or the related extraordinary media coverage on ADs in the years 2008-2010. The German law on ADs, however, involves no incentive or even recommendation for individuals to draw up an $\mathrm{AD}$, or for health care providers to encourage and support anyone doing so. Considering the disappointing experience with the - at the time much more ambitious - US Patient Self Determination Act of 1991 [5], it seems little realistic to expect a major effect of the law on the prevalence of ADs beyond what Hubert et al. have found already, or even that this moderate effect will be sustained.

Moreover, this survey confirms a gap between patients' expectations towards physicians and physicians' factual support with regard to ADs already known from other studies: Of the patients with an $\mathrm{AD}$, less than $10 \%$ drew it up following physician advice, $26 \%$ desired more information, and only 1 of 4 ADs was written with the assistance of a physician. Of the patients without an $\mathrm{AD}$, only 1 in 10 indicated that they were not interested in doing so, whereas more than 2 in 3 desired more information. Of all 377 patients whose physician had not addressed the topic, $52 \%$ wanted their physician to do so. In their discussion, the authors conclude that 'further investigations are required to identify and remedy the discrepancy' between patient expectations on the one hand and factual physician support on the other.

But, frankly speaking, is there any realistic prospect that after 4 decades of research and circular debate on ADs more of the same is likely to 'remedy the discrepancy' between what we wish ADs to achieve, and what they actually do? After all, the data of Hubert and colleagues point only to the tip of an iceberg. Since ADs are often not at hand when needed, the true availability of ADs in this sample is likely to be lower than the self-reported 1 in 3. Furthermore, physician-assisted advance planning is rare, so it remains unclear in how far the ADs represent an informed refusal. In addition, most of such ADs have shown to be forms [6] that in Germany often remain fairly vague, and do not help to guide clinically relevant treatment decisions. Moreover, in the absence of forms specifically designed for emergencies (i.e., physician's orders for life-sustaining treatment, POLST), poorly informed relatives or professional carers as well as emergency staff are likely to

\section{KARGER}

Fax +497614520714

Information@Karger.com

www.karger.com
(C) 2013 S. Karger GmbH, Freiburg

0378-584X/13/0367-0395\$38.00/0

Accessible online at:

www.karger.com/onk
Dr. med. Jürgen in der Schmitten, MPH

Institut für Allgemeinmedizin

Medizinische Fakultät der Heinrich-Heine-Universität

Moorenstr. 5, 40225 Düsseldorf, Germany

jids@med.uni-duesseldorf.de 
fall back on the familiar pathways leading to maximal care, even if ADs do imply something else [6].

Interestingly, there is a conceptional alternative to the traditional AD: Advance Care Planning (ACP), that while internationally on the rise (www.acpelsociety.com) seems to remain unnoticed by many, certainly in Germany where it is hardly known [7]. ACP begins with the recognition that traditional ADs could and will never work because they fail to provide a procedural approach on the individual level, and a systemic approach on the regional level [8]. The procedural approach implies repeated facilitated conversations of every eligible interested individual and his or her family with specifically skilled health care staff, resulting in written ADs (or advance care plans) that are updated on a regular basis or whenever necessary. Facilitated disease-specific planning, for example with cancer patients [9], takes the individual disease into account and helps the patient to shape his or her decisions for likely trajectories. The systemic, regional approach $[10,11] \mathrm{im}$ - plies: sufficient provision of trained facilitators and repeated active offers to every individual of the target population; meaningful, regionally uniform forms including a POLST equivalent to guide medical interventions in the emergency $[12,13]$; continual education of all relevant health care providers so they will understand, promote and follow advance care plans of this kind and origin; and a reiterative quality assurance process. Regional or institutional ACP programs make a difference to patients, families, and staff $[14,15]$, their implementation requires a significant regional effort, initiating nothing less than a cultural change [9], and they finally release us from the agonizing perpetuation of the pointless debate on how to promote traditional ADs.

\section{Disclosure Statement}

The author declares that he has no conflicts of interest.

\section{References}

1 Kutner L: Euthanasia: Due process for death with dignity; the living will. Indiana Law J 1969;44: 539-554.

2 Fagerlin A, Schneider CE: Enough. The failure of the living will. Hastings Cent Rep 2004;34:30-42.

$\checkmark 3$ Gross MD: What do patients express as their preferences in advance directives? Arch Intern Med 1998;158:363-365.

4 Hubert E, Schulte N, Belle S, Gerhardt A, Merx K, Hofmann W, Stein A, Burkholder I, Hofheinz R, Kripp M: Cancer patients and advance directives: a survey of patients in a hematology and oncology outpatient clinic. Onkologie 2013;36: DOI: 10.1159/000353604.

5 Teno J, Lynn J, Wenger N, Phillips RS, Murphy DP, Connors AF, Jr., Desbiens N, Fulkerson W, Bellamy P, Knaus WA: Advance directives for seriously ill hospitalized patients: Effectiveness with the patient self-determination act and the support intervention. Support investigators. Study to understand prognoses and preferences for outcomes and risks of treatment. J Am Geriatr Soc 1997; 45:500-507.

6 Sommer S, Marckmann G, Pentzek M, Wegscheider K, Abholz HH, in der Schmitten J: Advance directives in nursing homes: Prevalence, validity, significance, and nursing staff adherence. Dtsch Arztebl Int 2012;109:577-583.

7 in der Schmitten J, Marckmann G: [Advance directives: a dead end]. Zeitschrift für Medizinische Ethik 2013;59:227-240.

8 Hammes B, Briggs L: Building a systems approach to advance care planning manual. La Crosse, WI, USA, Respecting Choices, Gundersen Lutheran Medical Foundation, 2011.

9 Michael N, O`Callaghan C, Clayton J, Pollard A, Stepanov N, Spruyt O, Michael M, Ball D: Understanding how cancer patients actualise, relinquish, and reject advance care planning: Implications for practice. Support Care Cancer 2013;21:2195-2205.

10 Hammes BJ, Rooney BL, Gundrum JD: A comparative, retrospective, observational study of the prevalence, availability, and specificity of advance care plans in a county that implemented an advance care planning microsystem. J Am Geriatr Soc 2010;58:1249-1255.

11 in der Schmitten J, Rotharmel S, Mellert C, Rixen S, Hammes BJ, Briggs L, Wegscheider K, Marckmann G: A complex regional intervention to implement advance care planning in one town's nursing homes: Protocol of a controlled interregional study. BMC Health Serv Res 2011;11:14.
Hickman SE, Nelson CA, Perrin NA, Moss AH, Hammes BJ, Tolle SW: A comparison of methods to communicate treatment preferences in nursing facilities: Traditional practices versus the physician orders for life-sustaining treatment program. J Am Geriatr Soc 2010;58:1241-1248

13 in der Schmitten J, Rothärmel S, Rixen S, Marckmann G: [Advance directives in the emergency service (part 2). New perspectives by means of advance care planning and the 'Hausärztliche Anordnung für den Notfall' (family physician order for life-sustaining therapy in case of emergency)]. Notfall Rettungsmed 2011;6:10.

14 Detering KM, Hancock AD, Reade MC, Silvester $\mathrm{W}$ : The impact of advance care planning on end of life care in elderly patients: Randomised controlled trial. BMJ 2010;340:c1345.

15 Molloy DW, Guyatt GH, Russo R, Goeree R, O'Brien BJ, Bedard M, Willan A, Watson J, Patterson C, Harrison C, Standish T, Strang D, Darzins PJ, Smith S, Dubois S: Systematic implementation of an advance directive program in nursing homes: A randomized controlled trial. JAMA 2000;283:1437-1444. 